Article

\title{
Studies on the Chemical Diversities of Secondary Metabolites Produced by Neosartorya fischeri via the OSMAC Method
}

\author{
You-Min Ying ${ }^{1}$, Lu Huang ${ }^{1}$, Ting Tian ${ }^{1}$, Cui-Yu Li ${ }^{1}$, Shi-Lei Wang ${ }^{2}$, Lie-Feng Ma ${ }^{1}$, \\ Wei-Guang Shan ${ }^{1}$, Jian-Wei Wang ${ }^{1, *}$ and Zha-Jun Zhan ${ }^{1, *}$ \\ 1 College of Pharmaceutical Science, Zhejiang University of Technology, Hangzhou 310014, China; \\ ymying@zjut.edu.cn (Y.-M.Y.); 15958025120@163.com (L.H.); m17816037931@163.com (T.T.); \\ aalicuiyu@163.com (C.-Y.L.); maliefeng@zjut.edu.cn (L.-F.M.); tianranyaowu@zjut.edu.cn (W.-G.S.) \\ 2 College of Biology and Environment Engineering, Zhejiang Shuren University, Hangzhou 310015, China; \\ wangshilei1105@163.com \\ * Correspondence: wangjianwei@zjut.edu.cn (J.-W.W.); zjnpr@zjut.edu.cn (Z.-J.Z.); \\ Tel.: +86-571-88871075 (J.-W.W.); +86-571-88871030 (Z.-J.Z.)
}

Received: 22 September 2018; Accepted: 22 October 2018; Published: 25 October 2018

\begin{abstract}
The One Strain Many Compounds (OSMAC) method was applied to explore the chemical diversities of secondary metabolites produced by Neosartorya fischeri NRRL 181. Four pyripyropenes 1-4, eight steroids 5-11, and four prenylated indole alkaloids 12-15, were obtained from the fungus cultured in petri dishes containing potato dextrose agar (PDA). 1,7,11-trideacetylpyripyropene A (1) and 1,11-dideacetyl pyripyropene A (2) were obtained and spectroscopically characterized (1D, 2D NMR, and HR-ESI-MS) from a natural source for the first time. It offered a sustainable source of these two compounds, which were usually used as starting materials in preparing pyripyropene derivatives. In addition, as compared with all the other naturally occurring pyripyropenes, $\mathbf{1}$ and 2 possessed unique acetylation patterns that did not follow the established late-step biosynthetic rules of pyripyropenes. The natural occurrence of $\mathbf{1}$ and $\mathbf{2}$ in the fungus implied that the timing and order of hydroxylation and acetylation in the late-step biosynthetic pathway of pyripyropenes remained to be revealed. The isolation and identification of 1-15 indicated that the OSMAC method could remarkably alter the metabolic profile and enrich the chemical diversities of fungal metabolites. Compounds 1-4 exhibited no obvious cytotoxicity against the triple-negative breast cancer cell line MDA-MB-231 as compared with taxol.
\end{abstract}

Keywords: OSMAC; pyripyropenes; Neosartorya fischeri; secondary metabolites

\section{Introduction}

Filamentous fungi are prolific producers of bioactive natural products [1], as exemplified by the antibiotic penicillin [2] and the anti-hypercholesterolemia drug lovastatin [3]. In recent years, data from genome sequencing have revealed an inconsistency between the number of biosynthetic gene clusters (BGCs) identified as potentially encoding secondary metabolites and the actual number of chemically characterized secondary metabolites from any given fungi [4]. The reason underlying the phenomenon is that many BGCs are not expressed under laboratory conditions and are generally considered as silent or cryptic. Inducing the expression of these silent BGCs could unlock the chemical diversity they control, allowing the discovery of novel molecules of both medical and biotechnological interest. Therefore, both genetic and cultivation-based techniques have been developed aimed at stimulating expression of these silent BGCs [4]. The principles behind the cultivation based approaches have been conceptualized in the "one strain many compounds" (OSMAC) framework, which underlines 
how a single strain can produce different molecules when grown under different environmental conditions [5]. Unlike genetic manipulations, the OSMAC approach is not targeted to the activation of a specific cryptic gene cluster, but to the systematic alteration of readily accessible culturing parameters including medium components (salts, amino acids, and carbon source), $\mathrm{pH}$, culture aeration (including the type of culture vessel used), and temperature of growth [6]. This makes the OSMAC approach an accessible, versatile, inexpensive, and relatively simple tool for regulating the metabolism of fungi [6].

Neosartorya fischeri is a thermotolerance fungus belonging to the Aspergillus subgenus Fumigati subgroup Fumigati, and shares several common physical traits with Aspergillus fumigatus [7]. As compared with $A$. fumigatus, the secondary metabolites of $N$. fischeri have not been extensively studied and only resulted in the discovery of limited types of compounds [8]. Nevertheless, bioinformatics prediction by antiSMASH [9] revealed that the genome of $N$. fischeri NRRL181 harbored 39 BGCs, with 25 of them not related to any previously reported natural products (https:/ / fungismash.secondarymetabolites.org/upload/ fungi-d6eb54a9-0d96-4fa0bf97ba8be5065608/index.html), indicating great potential for mining the fungus for novel secondary metabolites. In our previous endeavor at discovering novel structures from fungi, we focused on two N. fischeri strains, i.e., N. fischeri CGMCC 3.5378 and N. fischeri NRRL181. In-depth studies on the secondary metabolites of $N$. fischeri CGMCC 3.5378 led to the isolation of five new prenylated indole alkaloids cultured on wheat bran [10,11] and moist corn [12], while the preliminary studies on $N$. fischeri NRRL181 furnished two new fumiquinazolines and a known compound pyripyropene A [13]. The promising bioactivities and rare natural occurrence of pyripyropenes [14,15] encouraged us to explore the chemical diversities of this kind of natural products. As guided by the OSMAC strategy, N. fischeri NRRL181 was cultured in 20 different conditions (Table S1) and analyzed for the production of pyripyropenes by HPLC. Herein, we report the isolation, structure characterization, and bioassay of the induced secondary metabolites from the fungus cultured in petri dishes containing PDA agar.

\section{Results}

When N. fischeri NRRL181 was cultured on PDA agar in Petri dishes, it gave the most abundant HPLC traces, including several peaks showing the characteristic UV absorption patterns of pyripyropenes (Figure S1). Subsequent chemical investigation on the extract led to the isolation and structure characterization of four pyripyropenes 1-4, eight steroids 5-11, and four prenylated indole alkaloids 12-15. The known compounds 3-15 were identified as 7-deacetylpyripyropene A (3) [16], pyripyropene A (4) [17], dankasterone A (5) [18], 22E,24R-ergosta-7,22-diene- $3 \beta, 5 \alpha, 6 \beta, 9 \alpha$-tetraol (6) [19], 22E,24R-ergosta-7,22-diene-3 $\beta, 5 \alpha, 6 \beta$-triol (7) [20], 3 $\beta, 5 \alpha, 9 \alpha$-trihydroxy-(22E,24R)-ergosta-7,

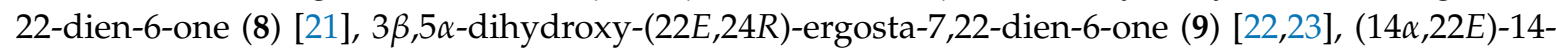
hydroxyergosta-7,22-diene-3,6-dione (10) [24], ergosterol (11) [25], 12 $\beta$-hydroxyverruculogen TR-2 (12) [26], verruculogen (13) [27], fumitremorgin A (14) [28], and acetylaszonalenin (15) [29] (Figure 1). 


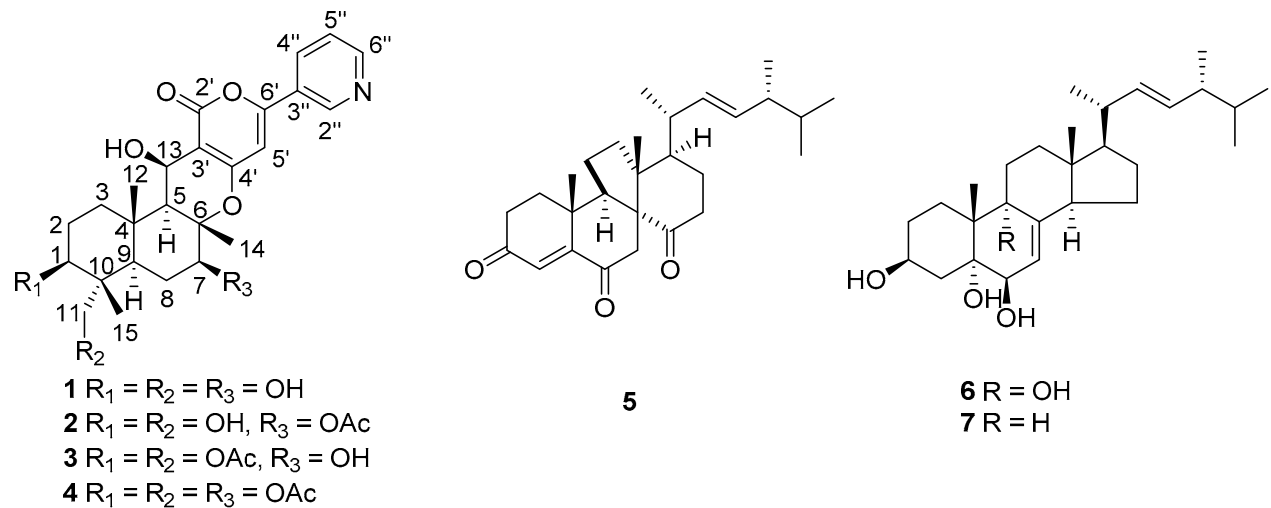

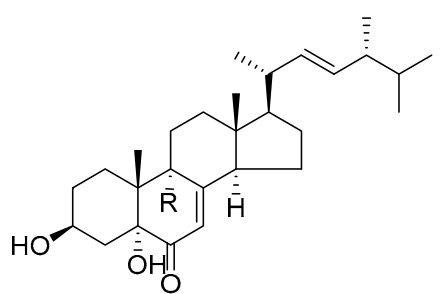

$8 \mathrm{R}=\mathrm{OH}$

$9 \mathrm{R}=\mathrm{H}$<smiles>[2H]C(C)(O)Cc1c2cc(n1C(O)C1(O)N(C)C(=O)C3CCCN31)-c1ccc(OC)cc1N2</smiles>

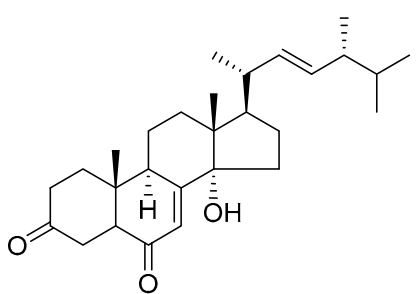

10

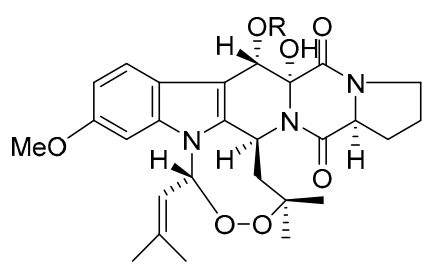

$13 \mathrm{R}=\mathrm{H}$

$14 \mathrm{R}=$ Prenyl<smiles>CC(C)C(C)/C=C/C(C)[C@H]1CCC2C3C=CC4CC(O)CCC4(C)C3CCC21C</smiles>

11<smiles>C=CC(C)(C)[C@]12C[C@H]3C(=O)Nc4ccccc4C(=O)N3[C@H]1N(C(C)=O)c1ccccc12</smiles>

15

Figure 1. Structures of compounds 1-15.

Compound 1 was obtained as a white amorphous powder. The molecular formula was established as $\mathrm{C}_{25} \mathrm{H}_{31} \mathrm{NO}_{7}$ based on the [M+H] $]^{+}$peak at $m / z 458.2164$ given by HR-ESI-MS, corresponding to eleven degrees of unsaturation. UV spectrum showed absorptions at 230 and $319 \mathrm{~nm}$. The IR spectrum exhibited absorption bands for $\mathrm{OH}\left(3294 \mathrm{~cm}^{-1}\right)$ and carbonyl $\left(1692 \mathrm{~cm}^{-1}\right)$ groups. In the ${ }^{1} \mathrm{H} \mathrm{NMR}$ spectrum of 1 , signals for five olefinic methines at $\delta_{\mathrm{H}} 6.86(\mathrm{~s}), 7.62(\mathrm{dd}, 8.0,5.0), 8.32$ (ddd, 8.5, 2.0, 1.5), $8.69(\mathrm{~d}, 3.5)$ and $9.07(\mathrm{~s})$ were readily discerned, along with three O-bearing methines at $\delta_{\mathrm{H}} 3.71$ $(\mathrm{dd}, 12.0,5.0), 3.83(\mathrm{dd}, 11.5,5.0)$ and $5.01(\mathrm{~d}, 4.0)$, one O-bearing methylene at $\delta_{\mathrm{H}} 3.35(\mathrm{~d}, 11.0)$ and $3.59(\mathrm{~d}, 11.0)$, three methyls at $\delta_{\mathrm{H}} 0.79(\mathrm{~s}), 1.45(\mathrm{~s})$, and $1.69(\mathrm{~s})$. The ${ }^{13} \mathrm{C}$ NMR and DEPT spectra of 1 showed 25 resonances attributable to eight quaternary carbons (one carbonyl at $\delta \mathrm{c} 165.4$, four olefinic at $\delta \mathrm{c} 104.4,129.3,158.1$ and 164.7, one O-bearing at $\delta \mathrm{c} 87.0,10$ methines (five olefinic at $\delta \mathrm{c} 101.2,125.5,134.9,147.4$ and 151.9 , and three O-bearing at $\delta \mathrm{c} 66.5,72.9$, and 78.4), four methylenes (one O-bearing at $\delta \mathrm{c} 66.5$ ) and three methyls. The NMR data of 1 were almost superimposable on those of pyripyropene A (4), except for the disappearance of signals ascribable to the three acetyl groups in 4 . These observations, along with the molecular formula, postulated that 1 should be a tri-deacetylated derivative of 4. A comparison of the chemical shifts and coupling constants of $\mathrm{H}-1, \mathrm{H}-13$, and $\mathrm{H}_{2}-11$ suggested the deacetyl site at C-1, C-13, and C-11, which was confirmed by comprehensive elucidation of the 2D NMR data $\left({ }^{1} \mathrm{H}-{ }^{1} \mathrm{H}\right.$ COSY, HSQC, HMBC, and NOESY) (Figure 2) of $\mathbf{1}$. Thus, $\mathbf{1}$ was finally established as 1,7,11-trideacetylpyripyropene A.

Compound 2 was obtained as a white amorphous powder with a molecular formula of $\mathrm{C}_{27} \mathrm{H}_{33} \mathrm{NO}_{8}$ according to the $[\mathrm{M}+\mathrm{H}]^{+}$peak at $m / z 500.2206$ in the HR-ESI-MS mass spectrum. The IR spectrum of 
2 also displayed the absorption bands for $\mathrm{OH}\left(3335 \mathrm{~cm}^{-1}\right)$ and carbonyl $\left(1696 \mathrm{~cm}^{-1}\right)$ groups, and the UV spectrum showed absorptions at 230 and $319 \mathrm{~nm}$. In the ${ }^{1} \mathrm{H}$ NMR spectrum of 2 , signals ascribable to four methyls at $\delta_{\mathrm{H}} 0.79(\mathrm{~s}), 1.45(\mathrm{~s}), 1.79(\mathrm{~s})$, and $2.19(\mathrm{~s})$, one O-bearing methylene at $\delta_{\mathrm{H}} 3.31$ $(\mathrm{d}, 11.0)$ and $3.56(\mathrm{~d}, 11.0)$, three O-bearing methines at $\delta_{\mathrm{H}} 3.73(\mathrm{dd}, 12.0,5.0), 5.08(\mathrm{dd}, 11.5,5.0)$, and $5.02(\mathrm{~d}, 3.5)$ can be well distinguished. Similar to 1, five distinct signals for olefinic $\mathrm{CH}$ atoms at $\delta_{\mathrm{H}} 6.84(\mathrm{~s}), 7.60(\mathrm{dd}, 8.0,5.0), 8.33(\mathrm{ddd}, 8.0,2.0,1.5), 8.67(\mathrm{dd}, 5.0,2.0)$, and $9.08(\mathrm{~s})$ were easily discerned. The ${ }^{13} \mathrm{C}$ NMR and DEPT 135 spectrum of 2 showed the presence of four methyls, four methylenes (with one O-bearing at $\delta_{\mathrm{C}} 66.7$ ), 10 methines (with three O-bearing at $\delta_{\mathrm{C}} 60.3,72.9$, and 80.1, five olefinic at $\delta_{\mathrm{C}} 101.1,125.4,134.9,147.4$, and 151.9), 10 quaternary carbons (with two carbonyls at $\delta_{\mathrm{C}} 172.2$ and 165.2, four olefinic at $\delta_{\mathrm{C}} 104.5,129.2,158.2$, and 164.2 , and one O-bearing at $\delta_{\mathrm{C}} 84.9$ ). The above data exhibited resemblances with 1 and pyripyropene A (4), suggesting a pyripyropene skeleton of 2. As compared to 1, additional signals (one methyl at $\delta_{\mathrm{H}} 2.19$ (s) and one carbonyl at $\delta_{\mathrm{C}}$ 172.2) ascribable to an acetyl group were observed. The additional acetyl group was deduced to be harbored at C-7 by comparing the chemical shifts of $\mathrm{H}-7$ and C-7 with those in $\mathbf{1}$ and $\mathbf{4}$, and it was also confirmed by the HMBC correlation from H-7 $\left(\delta_{\mathrm{H}} 5.08(\mathrm{dd}, 11.5,5.0)\right)$ to the carbonyl at $\delta_{\mathrm{C}} 172.2$. Compound 2 was finally identified as 1,11-dideacetylpyripyropene A on the basis of comprehensive elucidation of the 2D-NMR data (Figure 2).
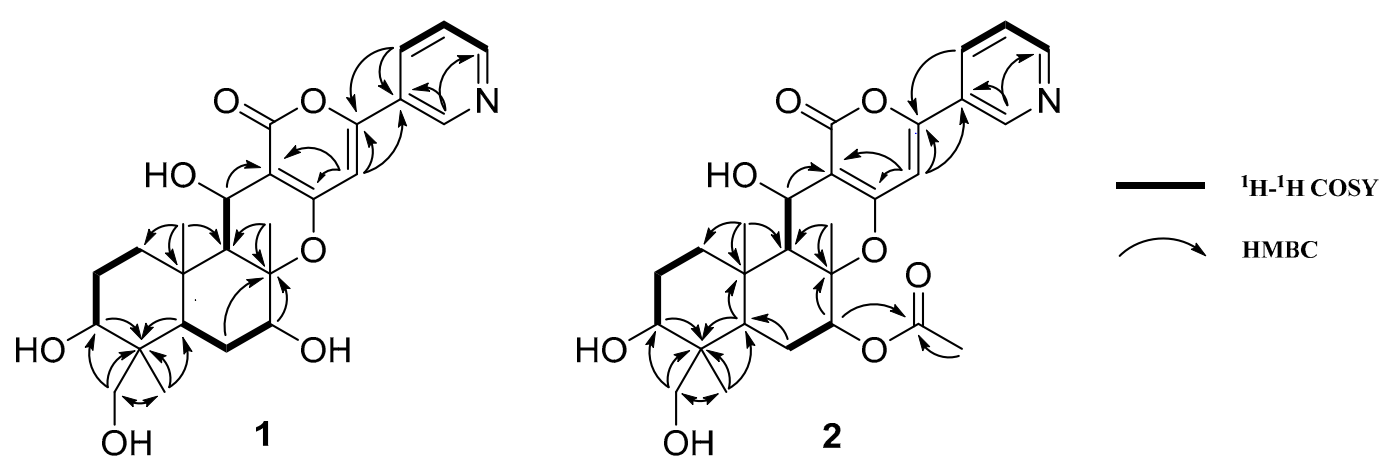

Figure 2. Key ${ }^{1} \mathrm{H}_{-}{ }^{1} \mathrm{H}$ COSY and $\mathrm{HMBC}$ correlations in $\mathbf{1}$ and $\mathbf{2}$.

As part of our ongoing screening of natural products against triple-negative breast cancer, compounds 1-4 were subjected to cytotoxicity assay against MDA-MB-231 cell line by the method we reported previously $[30,31]$. Unfortunately, none of them showed obvious activity as compared with the positive control, taxol.

\section{Discussion}

In the present work, OSMAC method was used to study the metabolic potential of the fungus N. fischeri NRRL181 and the chemical diversity of its secondary metabolites. Along with the targeted isolation of four pyripyropenes 1-4, eight steroids 5-11 and four prenylated indole alkaloids 12-15 were also identified from the fungus cultured on PDA agar in petri dishes. Compounds 1-3 and 5-10 have never been obtained in our previous chemical investigations on this fungus and were regarded as the induced metabolites. Compounds 5-10 are oxygenated steroids biogenetically related to ergosterol (11), with compound 5 featuring a rearranged 6/6/5/6 ring system. Their occurrence herein indicated that silent genes encoding the enzymes for rearrangement and oxidation may be activated in the present culturing condition and lead to the production of this series of oxygenated steroids.

Pyripyropenes are meroterpenoids first isolated from Aspergillus fumigatus by the Ōmura group [17]. To date, only 25 pyripyropenes bearing different substitution (hydroxyl, acetoxyl, or propionyloxy groups) at C-1, C-7, C-11 and C-13 of the terpenoid moiety have been obtained from natural sources, with pyripyropenes A-R from A. fumigatus FO-1289 and its mutant [17,32,33], pyripyropenes $\mathrm{S}-\mathrm{T}$ from $A$. similanensis $[34,35]$, 1-deacetylpyripyropene A, 11-deacetylpyripyropene $\mathrm{O}$ 
and 13-dehydroxy-1,11-deacetylpyripyropene A from Fusarium lateritium [36], 7-deacetylpyripyropene A (3) and 13-dehydroxylpyripyropene A from N. pseudofischeri [16]. Pyripyropenes, in particular pyripyropene A (4), were discovered as a highly potent selective inhibitor of the ACAT-2 isoform, which was considered a new therapeutic target for the treatment and prevention of hypercholesterolemia and atherosclerosis [14]. The in vivo efficacy of pyripyropene A (4) has also been proved [37]. Recently, pyripyropene A (4) has also gained attention as a promising lead for developing insecticides since it exhibited excellent insecticidal activity against aphids by both foliar application and soil drenching without serious toxicological issues [15,38,39]. Compounds 1 and 2 were previously prepared by chemical deacetylation of pyripyropene A (4) $[40,41]$ and used as starting materials in preparing pyripyropene derivatives. This is the first report on the isolation of the two compounds from a natural source, and the spectroscopic data were also completely reported and precisely assigned for the first time. The acquisition of them enriched the limited structure diversity of naturally occurring pyripyropenes and offered a sustainable way of preparing the two compounds. The BGC of pyripyropenes (pyr cluster) was identified in A. fumigatus Af293 by Itoh et al. [42], containing nine genes encoding one CoA ligase (pyr1), one polyketide synthase (pyr2), one terpene cyclase (pyr4), one flavin adenine dinucleotide dependent monooxygenase (pyr5), one prenyltransferase (pyr6), two cytochrome P450s (pyr3 and pyr9), and two acetyltransferases (pyr7 and pyr8). They also precisely proved the early steps in pyripyropenes biosynthesis, in which pyr1, pyr2, pyr6, pyr5, and pyr4 worked sequentially to construct the meroterpenoid core of pyripyropenes (deacetyl-pyripyropene E). However, the hydroxylation and acetylation mechanisms for the late steps were left unresolved. Hu et al. [43,44] identified the second BGC of pyripyropenes ( $p p b$ cluster) in another pyripyropene A producing strain Penicillium coprobium PF1169, where four tailoring genes ppb3, $p p b 4, p p b 8$, and $p p b 9$ were highly homologous to $p y r 3, p y r 9, p y r 7$, and $p y r 8$, respectively. By introducing the four tailoring genes individually into the model fungus $A$. oryzae and feeding the transformants with certain predicted intermediates, they reported the functions of ppb3 (P450-1), ppb4 (P450-2), ppb8 (AT-1), and ppb9 (AT-2), and proposed the mechanism for the late steps of pyripyropene biosynthesis $[43,44]$. According to the pathway they proposed, compounds $\mathbf{1}$ and $\mathbf{2}$ obtained in the present study were not on the pathway and should be considered as shunt products. However, given that the conclusion has been drawn based on the bioconversion of some predicted intermediates, it is reasonable to infer that one might get different results and depict different pathways if different intermediates were used. The natural occurrence of $\mathbf{1}$ and $\mathbf{2}$ in $N$. fischeri NRRL181 offered us with clues that the timing and order of hydroxylation and acetylation in the late-step biosynthetic pathway of pyripyropenes may be different from those reported. Hence, the mechanisms underlying these biosynthetic steps are still open and warrant further in vitro and in vivo studies.

\section{Materials and Methods}

\subsection{General Experimental Procedure}

All solvents used were of analytical grade and obtained from commercial sources. Solvents were filtered through a microporous membrane of $0.45 \mu \mathrm{m}$ before used for HPLC analyses. TLC: precoated silica gel $\mathrm{GF}_{254}$ plates (Qingdao Marine Chemical Co., Ltd., Qingdao, China); visualized by UV light and spraying with $10 \% \mathrm{H}_{2} \mathrm{SO}_{4}$ in $95 \% \mathrm{EtOH}$ followed by heating. Column chromatography (CC): silica gel ( $\mathrm{SiO}_{2}$; 200-300 mesh; Qingdao Marine Chemical Co., Ltd.), MCI CHP20P gel (75-150 $\mu \mathrm{m}$;

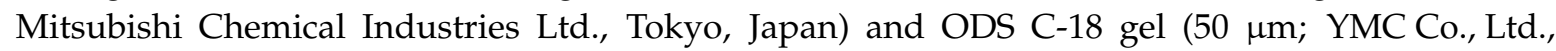
Kyoto, Japan). Optical rotations: Rudolph Research Autopol III automatic polarimeter. UV Spectra: Shimadzu-UV-2450 spectrometer; $\lambda_{\max }(\log \varepsilon)$ in $\mathrm{nm}$. IR Spectra: Thermo-Nicolet-6700 FT-IR microscope instrument (FT-IR microscope transmission). NMR spectra: Bruker AM-500 apparatus with chemical shifts given in ppm $(\delta)$ using TMS as an internal standard, J in Hz. ESI- and HR-ESI-MS: Agilent-6210-LC/TOF mass spectrometer; in $\mathrm{m} / \mathrm{z}$. 


\subsection{Fungus and Culture Conditions}

The fungus was purchased from DSMZ (DE-Braunschweig). The cultivation was carried out on static potato dextrose agar (PDA) medium at $30^{\circ} \mathrm{C}$ for 25 days.

\subsection{Extraction and Isolation}

The cultivated PDA medium along with the N. fischeri NRRL 181 mycelium was successively extracted with methanol (seven days each). The solvent was evaporated under reduced pressure to give a crude extract (13.8 g), which was then subjected to CC (MCI, $\left.\mathrm{MeOH} / \mathrm{H}_{2} \mathrm{O} 20: 80 \rightarrow 90: 10\right)$ to offer 10 fractions Frs. A-J. Fr. D and F were found to contain peaks with characteristic UV absorptions of pyripyropenes and were subjected to separation in priority. Fr. D was purified by CC (ODS C-18, $\left.\mathrm{MeOH} / \mathrm{H}_{2} \mathrm{O} 45: 55 \rightarrow 65: 35\right)$ to give six sub-fractions Frs. D1-D6. Fr. D6 was then separated by CC (ODS C-18; MeOH/ $\mathrm{H}_{2} \mathrm{O}$ 60:40) to furnish 3 (10.1 mg). Fr. F was separated by CC (ODS C-18, $\left.\mathrm{MeOH} / \mathrm{H}_{2} \mathrm{O} 60: 40 \rightarrow 90: 10\right)$ into six sub-fractions Frs. F1-F6. Fr. F5 was purified by CC on ODS C-18 $\left(\mathrm{MeOH} / \mathrm{H}_{2} \mathrm{O} 65: 35 \rightarrow 70: 30\right)$ to give $1(3.0 \mathrm{mg}), 2(10.0 \mathrm{mg})$, and 4 (11.1 $\left.\mathrm{mg}\right)$. Fr.F2 was purified by CC (ODS C-18; $\mathrm{MeOH} / \mathrm{H}_{2} \mathrm{O}$ 60:40) to give 15 (6.4 mg), and Fr. F6 was separated by CC (silica gel, petroleum ether/acetone 2:1) to furnish $6(9.1 \mathrm{mg})$. Fr. B was purified by CC (silica gel, petroleum ether/acetone 3.5:1 $\rightarrow 1: 1$ ) followed by CC (ODS C-18, MeOH/ $\left.\mathrm{H}_{2} \mathrm{O} 70: 30\right)$ to furnish 12 (7.8 mg). Fr. G was divided into $10 \mathrm{sub}$-fractions Fr. G1-G7 by CC (ODS C-18, $\left.\mathrm{MeOH} / \mathrm{H}_{2} \mathrm{O} 70: 30 \rightarrow 90: 10\right)$. 13 (35.4 mg) was crystallized from Fr. G2, while $8(12.7 \mathrm{mg})$ and $10(4.5 \mathrm{mg})$ was obtained from Fr. G4 by CC (silica gel, petroleum ether/acetone $5: 1 \rightarrow 3: 1$ ). Repeated CC purification (silica gel, petroleum ether/acetone $3: 1 \rightarrow 2: 1)$ of Fr. G5 furnished 7 (6.7 mg) and 9 (12.3 mg). Fr. H was first separated by CC (ODS C-18, $\mathrm{MeOH} / \mathrm{H}_{2} \mathrm{O}$ 75:25 $\left.\rightarrow 90: 10\right)$ to give five sub-fractions Fr. H1-H5. 5 (41.3 mg) and 14 (23.6 mg) were crystallized from Fr. H2 and Fr. H4, respectively. 11 (183 mg) was directly crystallized from Fr. J.

1,7,11-trideacetylpyripyropene A (1): white amorphous powder. $[\alpha]_{\mathrm{D}}^{25}=+40.0(\mathrm{c}=0.01, \mathrm{MeOH})$. UV $\lambda_{\max }(\log \varepsilon)(\mathrm{MeOH}): 320$ (0.8), 230 (1.0) 204 (0.8). IR (needle): 3294, 2957, 2924, 2876, 1692, $1579,1410,1296,1045 .{ }^{1} \mathrm{H}$ and ${ }^{13} \mathrm{C}$ NMR: see Table 1 . HR-ESI-MS $[\mathrm{M}+\mathrm{H}]^{+} \mathrm{m} / z$ 458.2164 (calcd for $\left.\mathrm{C}_{25} \mathrm{H}_{32} \mathrm{NO}_{7} 458.2173\right)$.

1,11-dideacetyl pyripyropene $A(2)$ : white amorphous powder. $[\alpha]_{D}^{25}=+63.3(\mathrm{c}=0.01, \mathrm{MeOH})$. UV $\lambda_{\max }$ $(\log \varepsilon)(\mathrm{MeOH}): 321$ (1.2), 230 (1.4) 203 (1.3). IR (needle): 3335, 2925, 1696, 1584, 1415, 1246, 1037. ${ }^{1} \mathrm{H}$ and ${ }^{13} \mathrm{C}$ NMR: see Table 1. HR-ESI-MS $[\mathrm{M}+\mathrm{H}]{ }^{+} m / z 500.2206$ (calcd for $\mathrm{C}_{27} \mathrm{H}_{34} \mathrm{NO}_{8}$ 500.2217).

Table 1. ${ }^{1} \mathrm{H}$ and ${ }^{13} \mathrm{C}$ NMR data of compounds 1 and 2 in $\mathrm{CD}_{3} \mathrm{OD}(\delta$ in ppm, $J$ in $\mathrm{Hz}){ }^{\mathrm{a}}$.

\begin{tabular}{|c|c|c|c|c|}
\hline \multirow{2}{*}{ Position } & \multicolumn{2}{|l|}{1} & \multicolumn{2}{|l|}{2} \\
\hline & $\delta_{\mathbf{H}}$ & $\delta_{\mathrm{C}}$ & $\delta_{\mathbf{H}}$ & $\delta_{\mathrm{C}}$ \\
\hline 1 & $3.71(\mathrm{dd}, 12.0,5.0)$ & 72.9 & $3.73(\mathrm{dd}, 12.0,5.0)$ & 72.9 \\
\hline 2 & $\begin{array}{l}1.80(\mathrm{~m}) \\
1.90(\mathrm{~m})\end{array}$ & 27.3 & $\begin{array}{l}1.72(\mathrm{~m}) \\
1.93(\mathrm{~m})\end{array}$ & 27.2 \\
\hline 3 & $\begin{array}{l}1.34(\mathrm{~m}) \\
2.16(\mathrm{~m})\end{array}$ & 37.7 & $\begin{array}{l}1.37(\mathrm{~m}) \\
2.17(\mathrm{~m})\end{array}$ & 37.5 \\
\hline 4 & - & 39.2 & - & 39.1 \\
\hline 5 & $1.44(\mathrm{~d}, 4.0)$ & 55.7 & $1.47(\mathrm{~d}, 4.0)$ & 55.8 \\
\hline 6 & - & 87.0 & - & 84.9 \\
\hline 7 & $3.83(\mathrm{dd}, 11.5,5.0)$ & 78.4 & $5.08(\mathrm{dd}, 11.5,5.0)$ & 80.1 \\
\hline 8 & $\begin{array}{l}1.63(\mathrm{~m}) \\
1.90(\mathrm{~m})\end{array}$ & 28.9 & $\begin{array}{l}1.44(\mathrm{~m}) \\
1.84(\mathrm{~m})\end{array}$ & 26.5 \\
\hline 9 & $1.51(\mathrm{dd}, 12.5,1.5)$ & 46.4 & $1.53(\mathrm{~d}, 2.0)$ & 46.3 \\
\hline 10 & - & 43.3 & - & 43.4 \\
\hline 11 & $\begin{array}{l}3.35(\mathrm{~d}, 11.0) \\
3.59(\mathrm{~d}, 11.0)\end{array}$ & 66.5 & $\begin{array}{l}3.31(\mathrm{~d}, 11.0) \\
3.56(\mathrm{~d}, 11.0)\end{array}$ & 66.7 \\
\hline 12 & $1.45(\mathrm{~s})$ & 18.0 & $1.45(\mathrm{~s})$ & 17.9 \\
\hline
\end{tabular}


Table 1. Cont.

\begin{tabular}{ccccc}
\hline \multirow{2}{*}{ Position } & \multicolumn{2}{c}{$\mathbf{1}$} & \multicolumn{2}{c}{$\mathbf{2}$} \\
\cline { 2 - 5 } & $\delta_{\mathbf{H}}$ & $\delta_{\mathbf{C}}$ & $\delta_{\mathbf{H}}$ & $\delta_{\mathbf{C}}$ \\
\hline 13 & $5.01(\mathrm{~d}, 4.0)$ & 60.5 & $5.02(\mathrm{~d}, 3.5)$ & 60.3 \\
14 & $1.69(\mathrm{~s})$ & 16.0 & $1.79(\mathrm{~s})$ & 17.0 \\
15 & $0.79(\mathrm{~s})$ & 12.7 & $0.79(\mathrm{~s})$ & 12.6 \\
16 & - & - & - & 172.2 \\
17 & - & - & $2.19(\mathrm{~s})$ & 21.2 \\
18 & - & - & - & - \\
19 & - & - & - & - \\
\hline $2^{\prime}$ & - & 165.4 & - & 165.2 \\
$3^{\prime}$ & - & 104.4 & - & 104.5 \\
$4^{\prime}$ & - & 164.7 & - & 164.2 \\
$5^{\prime}$ & - & 101.2 & $6.84(\mathrm{~s})$ & 101.1 \\
$6^{\prime}$ & $9.86(\mathrm{~s})$ & 158.1 & - & 148.2 \\
$2^{\prime \prime}$ & - & 147.4 & $9.08(\mathrm{~d}, 2.0)$ & 129.2 \\
$3^{\prime \prime}$ & $1.5)$ & 129.3 & - & 134.9 \\
$4^{\prime \prime}$ & $8.32(\mathrm{ddd}, 8.0,2.0$, & 134.9 & $8.33(\mathrm{ddd}, 8.0,2.0$, & $1.5)$ \\
$5^{\prime \prime}$ & $7.62(\mathrm{dd}, 8.0,5.0)$ & 125.5 & $7.60(\mathrm{dd}, 8.0,5.0)$ & 125.4 \\
$6^{\prime \prime}$ & 8.69 (brd, 3.5) & 151.9 & $8.67(\mathrm{dd}, 5.0,2.0)$ & 151.9 \\
\hline & a $500 \mathrm{MHz}$ for ${ }^{1} \mathrm{H}$ and $125 \mathrm{MHz}$ for ${ }^{13} \mathrm{C} \mathrm{NMR.}$ & \\
\hline
\end{tabular}

\subsection{Bioassay}

All isolates were evaluated for the cytotoxic activities against MDA-MB-231 cell line according to protocols we previously reported [30,31], employing taxol as the positive control.

\section{Conclusions}

By applying the OSMAC method to N. fischeri NRRL 181, four pyripyropenes, eight steroids, and four prenylated indole alkaloids, were obtained from the fungus cultured in petri dishes containing PDA medium. The results validated the effectiveness of the OSMAC method in diversifying the fungal secondary metabolites. The acquisition of the two new naturally-occurring pyripyropene derivatives may help to understand the late-step biosynthetic mechanism of pyripyropenes.

Supplementary Materials: The following are available online at http://www.mdpi.com/1420-3049/23/11/ 2772/s1. Culturing media screened in the present study (Table S1) and the NMR, HRMS, IR, and UV spectra of compounds 1 and 2 (Figures S1-S16).

Author Contributions: Y.-M.Y. and W.-G.S. conceived the idea; Y.-M.Y., Z.-J.Z., and J.-W.W. designed the experiment; Y.-M.Y., L.H., T.T., and C.-Y.L. performed the experiment and analyzed the data; S.-L.W. contributed the material; L.-F.M. performed the NMR experiments; Y.-M.Y. wrote the paper.

Funding: This research was funded by the Natural Science Foundation of Zhejiang Province (grant number LY17B020011) and the Science and Technology Plan Project of Zhejiang Province (grant numbers LGF18B020001 and 2016C33075).

Acknowledgments: The authors appreciate the help offered by the Research Center of Analysis and Measurement of Zhejiang University of Technology in obtaining the NMR and MS data of the compounds.

Conflicts of Interest: The authors declare no conflict of interest.

\section{References}

1. Schueffler, A.; Anke, T. Fungal natural products in research and development. Nat. Prod. Rep. 2014, 31, 1425-1448. [CrossRef] [PubMed]

2. Ozcengiz, G.; Demain, A.L. Recent advances in the biosynthesis of penicillins, cephalosporins and clavams and its regulation. Biotechnol. Adv. 2013, 31, 287-311. [CrossRef] [PubMed] 
3. Mulder, K.C.L.; Mulinari, F.; Franco, O.L.; Soares, M.F.; Magalhães, B.S.; Parachin, N.S. Lovastatin production: From molecular basis to industrial process optimization. Biotechnol. Adv. 2015, 33, 648-665. [CrossRef] [PubMed]

4. Romano, S.; Jackson, S.A.; Patry, S.; Dobson, A.D.W. Extending the "One Strain Many Compounds" (OSMAC) principle to marine microorganisms. Mar. Drugs 2018, 16, 244. [CrossRef] [PubMed]

5. Bode, H.B.; Bethe, B.; Höfs, R.; Zeeck, A. Big effects from small changes: Possible ways to explore nature's chemical diversity. ChemBioChem. 2002, 3, 619-627. [CrossRef]

6. Zarins-Tutt, J.S.; Barberi, T.T.; Gao, H.; Mearns-Spragg, A.; Zhang, L.X.; Newman, D.J.; Goss, R.J.M. Prospecting for new bacterial metabolites: A glossary of approaches for inducing, activating and upregulating the biosynthesis of bacterial cryptic or silent natural products. Nat. Prod. Rep. 2016, 33, 54-72. [CrossRef] [PubMed]

7. Girardin, H.; Monod, M.; Latgé, J.P. Molecular characterization of the food-borne fungus Neosartorya fischeri (Malloch and Cain). Appl. Environ. Microb. 1995, 61, 1378-1383.

8. Frisvad, J.C.; Larsen, T.O. Extrolites of Aspergillus fumigatus and other pathogenic species in Aspergillus section Fumigati. Front. Microbiol. 2016, 6, 1485-1498. [CrossRef] [PubMed]

9. Weber, T.; Blin, K.; Duddela, S.; Krug, D.; Kim, H.U.; Bruccoler, R.; Lee, S.Y.; Fischbach, M.A.; Müller, R.; Wohlleben, W.; et al. antiSMASH 3.0-a comprehensive resource for the genome mining of biosynthetic gene clusters. Nucleic Acids Res. 2015, 43, W237-W243. [PubMed]

10. Zheng, Z.Z.; Shan, W.G.; Wang, S.L.; Ying, Y.M.; Ma, L.F.; Zhan, Z.J. Three new prenylated diketopiperazines from Neosartorya fischeri. Helv. Chim. Acta 2014, 97, 1020-1026. [CrossRef]

11. Chen, B.Y.; Wang, Z.; Ying, Y.M.; Jiang, L.X.; Zhan, Z.J.; Wang, J.L.; Zhang, W.; Neofipiperzine, D. A new prenylated indole alkaloid metabolite of the fungus Neosartorya fischeri. J. Chem. Res. 2014, 38, 539-541.

12. Shan, W.G.; Wang, S.L.; Ying, Y.M.; Ma, L.F.; Zhan, Z.J. Indole-benzodiazepine-2,5-dione derivatives from Neosartorya fischeri. J. Chem. Res. 2014, 38, 692-694. [CrossRef]

13. Shan, W.G.; Wang, S.L.; Lang, H.Y.; Chen, S.M.; Ying, Y.M.; Zhan, Z.J. Cottoquinazolines E and F from Neosartorya fischeri NRRL 181. Helv. Chim. Acta 2015, 98, 552-556. [CrossRef]

14. Ohshiro, T.; Rudel, L.L.; Ōmura, S.; Tomoda, H. Selectivity of microbial acyl-CoA: Cholesterol acyltransferase inhibitors toward isozymes. J. Antibiot. 2007, 60, 43-51. [CrossRef] [PubMed]

15. Horikoshi, R.; Goto, K.; Mitomi, M.; Oyama, K.; Sunazuka, T.; Ōmura, S. Identification of pyripyropene A as a promising insecticidal compound in a microbial metabolite screening. J. Antibiot. 2017, 70, 1-5. [CrossRef] [PubMed]

16. Lan, W.J.; Fu, S.J.; Xu, M.Y.; Liang, W.L.; Lam, C.K.; Zhong, G.H.; Xu, J.; Yang, D.P.; Li, H.J. Five new cytotoxic metabolites from the marine fungus Neosartoya pseudofischri. Mar. Drugs 2016, 14, 18. [CrossRef] [PubMed]

17. Ōmura, S.; Tomoda, H.; Kim, Y.K.; Nishida, H. Pyripyropenes, highly potent inhibitors of acyl-CoA:cholesterol acyltransferase produced by Aspergillus fumigatus. J. Antibiot. 1993, 46, 1168-1169. [CrossRef] [PubMed]

18. Amagata, T.; Tanaka, M.; Yamada, T.; Doi, M.; Minoura, K.; Ohishi, H.; Yamori, T.; Numata, A. Variation in cytostatic constituents of a sponge-derived Gymnascella dankaliensis by manipulating the carbon source. J. Nat. Prod. 2007, 70, 1731-1740. [CrossRef] [PubMed]

19. Chen, P.; Wu, J.; Dai, H.F.; Xie, X.C.; Mei, W.L. Chemical constituents from Cephalotaxus endophytic fungus S26 of hainanensis. Chin. J. Med. Chem. 2008, 18, 279-283.

20. Piccialli, V.; Sica, D. Four new trihydroxylated sterols from the sponge Spongionella gracillis. J. Nat. Prod. 1987, 50, 915-920. [CrossRef]

21. Xiong, H.Y.; Fei, D.Q.; Zhou, J.S.; Yang, C.J.; Ma, G.L. Steroids and other constituents from the mushroom Armillaria lueovirens. Chem. Nat. Compd. 2009, 45, 759-761. [CrossRef]

22. Ishizuka, T.; Yaoita, Y.; Kikuchi, M. Sterol constituents from the fruit bodies of Grifola frondosa (Fr.) S. F. Gray. Chem. Pharm. Bull. 1997, 45, 1756-1760. [CrossRef]

23. Yang, S.P.; Xu, J.; Yue, J.M. Sterols from the fungus Catathelasma imperiale. Chin. J. Chem. 2003, 21, $1390-1394$. [CrossRef]

24. Huang, H.C.; Liaw, C.C.; Yang, H.L.; Hseu, Y.C.; Kuo, H.T.; Tsai, Y.C.; Chien, S.C.; Amagaya, S.; Chen, Y.C.; Kuo, Y.H. Lanostane triterpenoids and sterols from Antrodia camphorate. Phytochemistry 2012, 84, 177-183. [CrossRef] [PubMed]

25. Kang, J.; Wang, H.Q.; Chen, R.Y. Studies on the constituents of the mycelia produced from fermented culture of Flammulina velutipes. Int. J. Med. Mushrooms 2003, 5, 391-396. [CrossRef] 
26. Li, X.J.; Zhang, Q.; Zhang, A.L.; Gao, J.M. Metabolites from Aspergillus fumigatus, an endophytic fungus associated with melia azedarach, and their antifungal, antifeedant and toxic activities. J. Agric. Food Chem. 2012, 60, 3424-3431. [CrossRef] [PubMed]

27. Afiyatullov, S.S.; Kalinovskii, A.I.; Pivkin, M.V.; Dmitrenok, P.S.; Kuznetsova, T.A. Fumitremorgins from the marine isolate of the fungus Aspergillus fumigatus. Chem. Nat. Compd. 2004, 40, 615-617. [CrossRef]

28. Yamazaki, M.; Fujimoto, H.; Kawasaki, T. Chemistry of tremorogenic metabolites. I. Fumitremorgin A from Aspergillus fumigatus. Chem. Pharm. Bull. 1980, 28, 245-254. [CrossRef] [PubMed]

29. Kimura, Y.; Hamasaki, T.; Nakajima, H.; Isogai, A. Structure of aszonalenin, a new metabolite of Aspergillus zonatus. Tetrahedron Lett. 1982, 23, 225-228. [CrossRef]

30. Tang, L.; Fu, L.L.; Lu, C.H.; Hou, X.R.; Shan, W.G.; Zhan, Z.J. New cytotoxic phloroglucinol derivatives from Agrimonia pilosa. Fitoterapia 2017, 118, 69-72. [CrossRef] [PubMed]

31. Zhao, H.; Wu, R.; Ma, L.F.; Wo, L.K.; Hu, Y.Y.; Chen, C.; Zhan, Z.J. Aurovertin-type polyketides from Calcarrisporium arbuscular with potent cytotoxic activities against triple-negative breast cancer. Helv. Chim. Acta 2016, 99, 543-546. [CrossRef]

32. Tomoda, H.; Tabata, N.; Yang, D.J.; Takayanagi, H.; Nishida, H.; Ōmura, S. Pyripyropenes, novel ACAT inhibitors produced by Aspergillus fumigatus III. Structure elucidation of pyripyropenes E. to L. J. Antibiot. 1995, 48, 495-503. [CrossRef] [PubMed]

33. Tomoda, H.; Tabata, N.; Yang, D.J.; Namatame, I.; Tanaka, H.; Ōmura, S. Pyripyropenes, novel ACAT inhibitors produced by Aspergillus fumigatus IV. Structure elucidation of pyripyropenes M. to R. J. Antibiot. 1996, 49, 292-298. [CrossRef] [PubMed]

34. Prompanya, C.; Dethoup, T.; Bessa, L.J.; Pinto, M.M.M.; Gales, L.; Costa, P.M.; Silva, A.M.S.; Kijjoa, A. New isocoumarin derivatives and meroterpenoids from the marine sponge-associated fungus Aspergillus similanensis sp. Nov. KUFA 0013. Mar. Drugs 2014, 12, 5160-5173. [PubMed]

35. Prompanya, C.; Fernandes, C.; Cravo, S.; Pinto, M.M.M.; Dethoup, T.; Silva, A.M.S.; Kijjoa, A. A new cyclic hexapeptide and a new isocoumarin derivative from the marine sponge-associated fungus Aspergillus similanensis sp. Nov. KUFA 0013. Mar. Drugs 2015, 13, 1432-1450. [CrossRef] [PubMed]

36. Cao, Q.X.; Wei, J.H.; Deng, R.; Feng, G.K.; Zhu, X.F.; Lan, W.J.; Li, H.J. Two new pyripyropenes from the marine fungus Fusarium lateritium 2016F18-1. Chem. Biodivers. 2017, 14, e1600298. [CrossRef] [PubMed]

37. Ohshiro, T.; Ohtawa, M.; Nagamitsu, T.; Matsuda, D.; Yagyu, H.; Davis, M.A.; Rudel, L.L.; Ishibashi, S.; Tomaoda, H. New pyripyropene A. derivatives, highly SOAT2-selective inhibitors, improve hypercholesterolemia and atherosclerosis in athrogenic mouse models. J. Pharmacol. Exp. Ther. 2015, 355, 297-307. [CrossRef] [PubMed]

38. Fuse, S.; Matsumura, K.; Johmoto, K.; Uekusa, H.; Tanaka, H.; Hirose, T.; Sunazuka, T.; Ōmura, S.; Takahashi, T. The design, synthesis, and evaluation of 1,5,7-trisubstituted-3-pyridyl-xathones for use as insecticides starting from pyripropene A. Chem. Eur. J. 2016, 22, 18450-18455. [CrossRef] [PubMed]

39. Goto, K.; Horikoshi, R.; Mitomi, M.; Oyama, K.; Hirose, T.; Sunazuka, T.; Ōmura, S. Synthesis and insecticidal efficacy of pyripyropene derivatives focusing on the C-1, C-7, and C-11 positions' substituent groups. J. Antibiot. 2018, 71, 1-5. [CrossRef] [PubMed]

40. Obata, R.; Sunazuka, T.; Li, Z.R.; Tian, Z.M.; Harigaya, Y.; Tabata, N.; Tomoda, H.; Ōmura, S. Chemical modification and structure-activity relationship of pyripyropenes 1 . Modification at the four hydroxyl groups. J. Antibiot. 1996, 49, 1133-1148. [CrossRef] [PubMed]

41. Obata, R.; Sunazuka, T.; Harigaya, Y.; Hayashi, M.; Rho, M.C.; Tomoda, H.; Ōmura, S. Structure-activity relationships study of pyripyropenes: Reversal of cancer cell multidrug resistance. J. Antibiot. 2000, 53, 422-425. [CrossRef] [PubMed]

42. Itoh, T.; Tokunaga, K.; Matsuda, Y.; Fujii, I.; Abe, I.; Ebizuka, Y.; Kushiro, T. Reconstitution of a fungal meroterpenoid biosynthesis reveals the involvement of a novel family of terpene cyclase. Nat. Chem. 2010, 2, 858-864. [CrossRef] [PubMed] 
43. Hu, J.; Okawa, H.; Yamamoto, K.; Oyama, K.; Mitomi, M.; Anzai, H. Characterization of two cytochrome P450 monoxygenase genes of the pyripyropene biosynthetic gene cluster from Penicillium coprobium. J. Antibiot. 2011, 64, 221-227. [CrossRef] [PubMed]

44. Hu, J.; Furutani, A.; Yamamoto, K.; Oyama, K.; Mitomi, M.; Anzai, H. Characterization of two acetyltransferase genes in the pyripyropene biosynthetic gene cluster from Penicillium coprobium. Biotechnol. Biotec. Equip. 2014, 28, 818-826. [CrossRef] [PubMed]

Sample Availability: Samples of the compounds 1-15 are available from the authors.

(C) 2018 by the authors. Licensee MDPI, Basel, Switzerland. This article is an open access article distributed under the terms and conditions of the Creative Commons Attribution (CC BY) license (http://creativecommons.org/licenses/by/4.0/). 